\title{
ITO-Ag alloy-ITO film with stable and high conductivity depending on the control of atomically flat interface
}

\author{
Shi-Wei Chen, Chun-Hao Koo* \\ Department of Materials Science and Engineering, National Taiwan University, No. 1, Sec. 4, Roosevelt Road, Taipei 106, Taiwan, ROC \\ Received 16 August 2006; accepted 11 January 2007 \\ Available online 26 January 2007
}

\begin{abstract}
The conductivity of ITO-Ag-ITO films declines with the deposition temperature increased above $200{ }^{\circ} \mathrm{C}$, because the surfaces of $\mathrm{Ag}$ layers become rough that scatter the conduction carriers. The solid-solution $\mathrm{Ag}-\mathrm{Ti}$ alloy and $\mathrm{Ag}-\mathrm{Ti}-\mathrm{Cu}$ alloy are developed to improve the stability of the surface morphology of Ag layers. This research proves that the Ag-Ti film can keep a smooth surface at an even higher deposition temperature. This leads ITO-AgTi-ITO films to have low resistivity at high deposition temperatures. However, further addition of Cu atoms into $\mathrm{Ag}-\mathrm{Ti}$ films causes several spikes formed on the surfaces probably relative to the relaxation of strain energy. The conductivity of the ITO-AgTiCu-ITO film will decline when a large amount of spikes is formed on the surface of $\mathrm{Ag}-\mathrm{Ti}-\mathrm{Cu}$ layer at a high deposition temperature.
\end{abstract}

(C) 2007 Elsevier B.V. All rights reserved.

Keywords: Surface morphology; $\mathrm{Ag}-\mathrm{Ti}$ alloy; $\mathrm{Ag}-\mathrm{Ti}-\mathrm{Cu}$ alloy; Resistivity

\section{Introduction}

High performance flat panel displays (FPD), especially the current-driving OLED device, require transparent electrodes with even lower resistivity. ITO, traditionally used, with higher resistivity seems not good enough to meet the requirement.

Using ITO-Metal-ITO (IMI) multilayer structures $[1,2]$ is the simplest and most effective way to improve the conductivity of electrodes. IMI structures have quite lower sheet resistance than ITO, although the transparency is slightly lower than ITO. The properties of IMI films are strongly dependent on the intermediate layer [1,2]. Silver is the best choice as the intermediate layer of IMI films, because it possesses both the greatest transparency and conductivity than other metals when the thickness of films gets very thin [3]. The appropriate thickness of the silver layer is about $10 \mathrm{~nm}$. However, ultra-thin silver films are not stable and easily form rough surfaces especially at a high deposition temperature [4]. This will decline the conductivity and transparency of IMI films.

\footnotetext{
* Corresponding author.

E-mail address: chkoo@ntu.edu.tw (C.-H. Koo).
}

Several researches $[4,5]$ proposed to smoothen and stabilize the surface morphology of silver films as deposition by alloying. However, the role of alloying elements was not explored. In this investigation, new solid-solution $\mathrm{Ag}-\mathrm{Ti}$ and $\mathrm{Ag}-\mathrm{Ti}-\mathrm{Cu}$ alloy films are developed to stabilize the surface morphology of ultra-thin silver films. Doping Ti or $\mathrm{Cu}$ atoms is proposed to dominate the surface morphology of ultra-thin silver films by governing growth behavior. It is discussed according to the bonding force between alloying atoms and $\mathrm{Ag}$ atoms.

The bonding force between $\mathrm{Ag}$ and $\mathrm{Ti}$ atoms is stronger than that between $\mathrm{Ag}$ atoms. According to the statistical mixing model [6], it is because the mixing enthalpy of $\mathrm{Ag}-\mathrm{Ti}$ regular solution shows a negative quantity, as proposed by Pan and et al. [7]. However, the $\mathrm{Ag}-\mathrm{Cu}$ solid solution possesses positive mixing enthalpy [8]. By a similar consideration, this indicates that the bonding force between $\mathrm{Ag}$ and $\mathrm{Cu}$ atoms is weaker than that between $\mathrm{Ag}$ atoms.

On the other hand, $\mathrm{Ag}-\mathrm{Ti}$ or $\mathrm{Ag}-\mathrm{Ti}-\mathrm{Cu}$ alloy is, replacing pure Ag, applied as the intermediate layer of ITO-Silver-ITO films. The resistivity is discussed according to the interface morphology. 


\section{Experimental}

IMI (ITO-Metal-ITO) films were deposited on the glass substrate (coring 7059) by continuous magnetron sputtering without vacuum breaking. The thickness was $45-10-45 \mathrm{~nm}$. ITO films were deposited using a sintered ITO target with high density and a RF power source. Ag or Ag alloys were used as metal targets with a DC power source. The purity of all targets is 99.99\%. The composition of alloy was $\mathrm{Ag}-0.5 \mathrm{wt} . \% \mathrm{Ti}$ and $\mathrm{Ag}-$ 0.5 wt. $\% \mathrm{Ti}-1$ wt. $\% \mathrm{Cu}$, both within the limitation of solid solution, in order to avoid too much decline in conductivity. Deposition was conducted at a pressure of 5 mTorr in an atmosphere of extra pure Ar. The chamber equipped with a cyro pump had a base pressure of $5 \times 10^{-6}$ Torr. The deposition temperature varied from 25 to $350{ }^{\circ} \mathrm{C}$. AFM (atomic force microscopy) was used to measure the thickness of the films and estimate the sputtering rate. The four-point probe method was used to measure the resistivity.

Only Metal/ITO (Metal = Ag, Ag-Ti, Ag-Ti-Cu) films with $10-45 \mathrm{~nm}$ in thickness were also produced by the same process. The surfaces were observed by AFM.

\section{Results and discussion}

\subsection{Surface morphology of silver films}

The surface of Ag films changes from smooth to rough at the deposition temperature above $200{ }^{\circ} \mathrm{C}$, as shown in Fig. 1(a)-(c). The

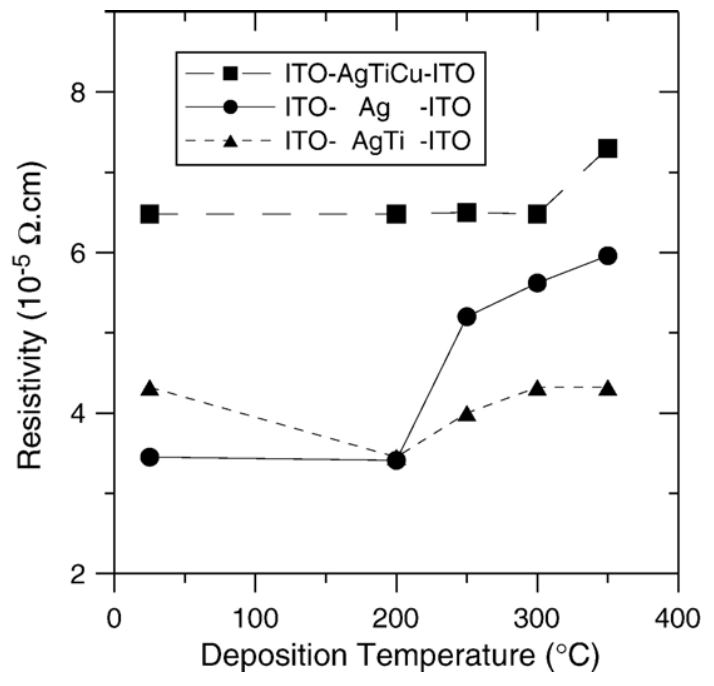

Fig. 2. Resistivity of IMI films depending on the deposition temperature.

rough surface may be caused by the formation of the island structure under low nucleation density led by the high deposition temperature, as proposed by Choi et al. [9].

However, Ag-Ti films can keep a smooth surface at an even higher deposition temperature (Fig. 1(d)). It is supposed that, in the initial stage of deposition, Ag adatoms around Ti adatoms tend to bond with $\mathrm{Ti}$ adatoms, forming initial clusters. Because the bonding force between $\mathrm{Ag}$ and $\mathrm{Ti}$ atoms is stronger than that between $\mathrm{Ag}$ atoms, the addition of $\mathrm{Ti}$ atoms distributed uniformly seems to increase the

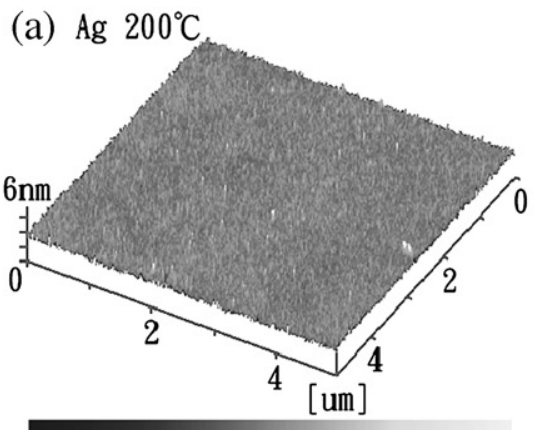

0.00

2. 69 (b) $\mathrm{Ag} 250^{\circ} \mathrm{C}$

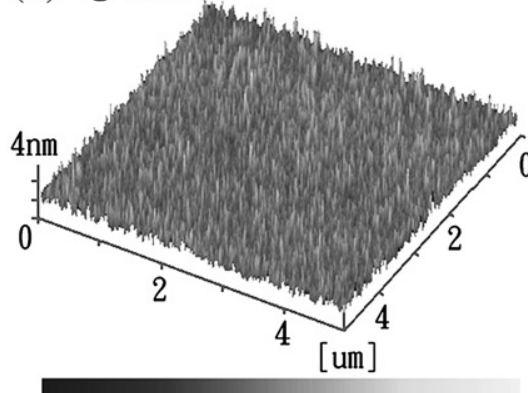

0.00

5. 00 (d) $\mathrm{AgTi} 350^{\circ} \mathrm{C}$

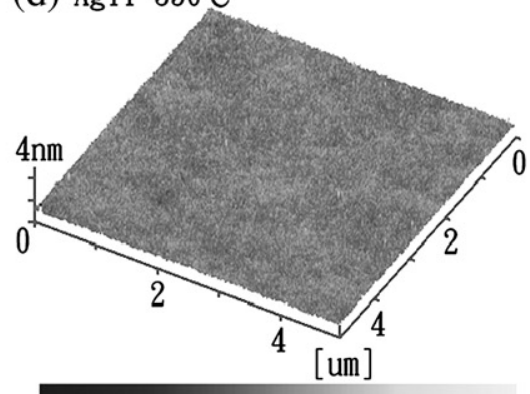

0.00

1. 24

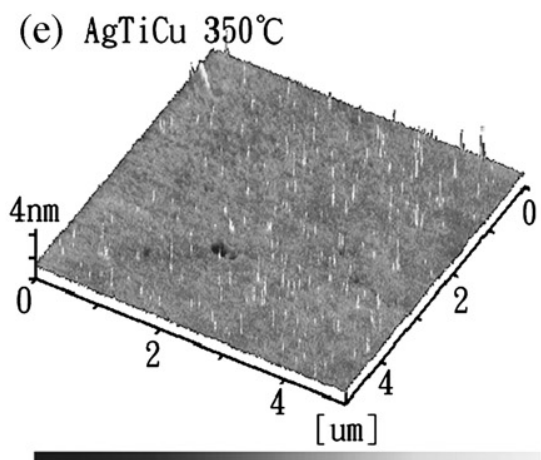

(c) $\mathrm{Ag} 350^{\circ} \mathrm{C}$

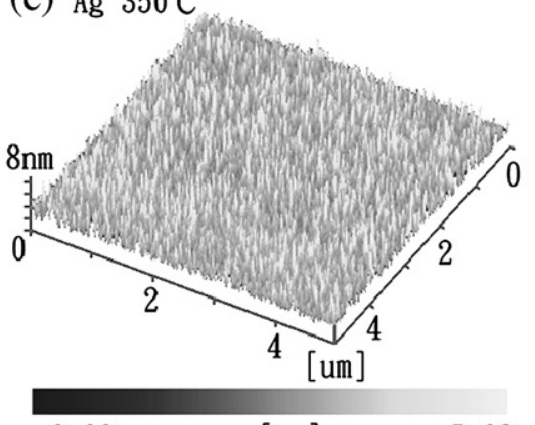

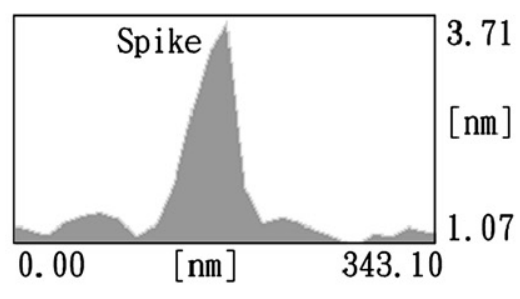

1. 17

Fig. 1. Surface morphology of Ag and Ag alloy films deposited on ITO at various temperatures, observed by AFM. (a) Ag film deposited at $200{ }^{\circ} \mathrm{C}$. (b) $\mathrm{Ag}$ film deposited at $250{ }^{\circ} \mathrm{C}$. (c) $\mathrm{Ag}$ film deposited at $350{ }^{\circ} \mathrm{C}$. (d) $\mathrm{Ag}-\mathrm{Ti}$ film deposited at $350{ }^{\circ} \mathrm{C}$. (e) $\mathrm{Ag}-\mathrm{Ti}-\mathrm{Cu}$ film deposited at $350{ }^{\circ} \mathrm{C}$. 
nucleation density of Ag films. This causes the formation of the 2D layer structure, resulting in the smooth surface.

The stability of the surface morphology of Ag-Ti films will decline by further addition of $\mathrm{Cu}$ atoms. As shown in Fig. 1(e), although the layer structure remained also and the atomically smooth matrix is presented, there are spikes formed on the surface of $\mathrm{Ag}-\mathrm{Ti}-\mathrm{Cu}$ films when films are deposited at $350{ }^{\circ} \mathrm{C}$. The spikes might be formed supposedly by the migration of the $\mathrm{Ag}$ adatoms that bond with $\mathrm{Cu}$ atoms. The bonding linked with $\mathrm{Cu}$ atoms is expected to be the weakest among the solid-solution $\mathrm{Ag}-\mathrm{Ti}-\mathrm{Cu}$ alloy and is easy to be broken. These Ag adatoms on the matrix might migrate to the outermost surface and form the spikes relative to the relaxation of the strain energy. The strain energy could be produced due to the difference in the lattice parameters between the $\mathrm{Ag}$ alloy layer (unstrained $\mathrm{Ag}$ with $\mathrm{FCC}$ structure, $d_{111}=2.35 \AA[10]$ ) and ITO (cubic structure, $d_{222}=2.92 \AA$ [11]) substrate. The relaxation of strain energy at a high deposition temperature accompanying the formation of spikes is fairly common and observed in the strained films [12].

The smooth matrix on the surface of $\mathrm{Ag}-\mathrm{Ti}-\mathrm{Cu}$ films is expected to be contributed by the doping Ti atoms. The solid-solution Ag-Ti alloy is expected to strengthen the surface structure according to the stronger bonding force between $\mathrm{Ag}$ and $\mathrm{Ti}$ atoms than that between $\mathrm{Ag}$ atoms. Therefore, the relaxation of strain energy and variation in morphology are retarded.

\subsection{Resistivity}

The thickness of silver films applied for the intermediate layer of IMI films is $10 \mathrm{~nm}$ and is smaller than the mean free path of pure Ag $(59 \mathrm{~nm})$ [13]. The surface (interface) roughness is expected to play important roles in the conductivity of ultra-thin Ag films and ITO-AgITO films.

Fig. 2 presents the variation in the resistivity of the IMI films with deposition temperature. The resistivity of the ITO-Ag-ITO films is stable at $200{ }^{\circ} \mathrm{C}$ but increases with the deposition temperature above $200{ }^{\circ} \mathrm{C}$. It is expected to be caused by the change in the surface morphology of $\mathrm{Ag}$ films from smooth to rough, as shown in Fig. 1, meanwhile, increasing the probability that conduction carriers are scattered by the rough interface among ITO-Ag-ITO films.

In contrast, the ITO-AgTi-ITO films are very stable. Their conductivity is good even at a higher deposition temperature. The resistivity is lower than that of ITO-Ag-ITO films above $200{ }^{\circ} \mathrm{C}$, apparently because Ag-Ti layers can keep smooth surfaces at a high deposition temperature (Fig. 2).

The resistivity of ITO-AgTiCu-ITO films apparently increases at the deposition temperature above $300{ }^{\circ} \mathrm{C}$. It is expected to be caused by the spikes formed on the surface of $\mathrm{Ag}-\mathrm{Ti}-\mathrm{Cu}$ films as shown in Fig. 1, causing the scattering of the conduction carriers at the interface among ITO-AgTiCu-ITO films. However, in our pre-study, only a few spikes are formed below $300{ }^{\circ} \mathrm{C}$ and spikes with a small amount seem to have an insignificant effect on the resistivity of ITO-AgTiCu-ITO films. Therefore, ITO-AgTiCu-ITO films have stable values of resistivity.

\section{Conclusions}

The results show that interface morphology plays an important role in the conductivity of IMI films. The IMI film with stable and high conductivity can be realized by using the solid-solution $\mathrm{Ag}-\mathrm{Ti}$ alloy as the intermediate layer because the Ag-Ti alloy film owns a stable and smooth surface.

\section{References}

[1] M. Fahland, P. Karlsson, C. Charton, Thin Solid Films 392 (2001) 334.

[2] E. Bertran, C. Corbella, M. Vives, A. Pinyol, C. Person, I. Porqueras, Solid State Ionics 165 (2003) 139.

[3] Y. Guan, M.A. Matin, T.M. Stephen, Electron. Lett. 39 (2002) 826.

[4] T. Suzuki, Y. Abe, M. Kawamura, K. Sasaki, T. Shouzu, K. Kawamata, Vacuum 66 (2002) 501.

[5] W.M. Kim, D.Y. Ku, I.k. Lee, Y.W. Seo, B.k. Cheong, T.S. Lee, I.H. Kim, K.S. Lee, Thin Solid Films 473 (2005) 315.

[6] D.V. Ragone, Thermodynamics of Materials, vol. I, John Wiley and Sons, Inc., 1995, p. 188.

[7] W. Pan, R. Li, J. Chen, R. Sun, J. Lian, Mater. Sci. Eng., A Struct. Mater.: Prop. Microstruct. Process. 287 (2000) 72.

[8] M. Bienzle, T. Oishi, F. Sommer, Mater. Trans. 33 (1992) 51.

[9] K.H. Choi, J.Y. Kim, Y.S. Lee, H.J. Kim, Thin Solid Films 341 (1999) 152.

[10] N. Yamada, I. Yasui, H. Li, Y. Ujihara, K. Nomura, Jpn. J. Appl. Phys. 38 (1999) 2856.

[11] L.G. Lin, W.A. Bassett, J. Appl. Phys. 44 (1993) 1475.

[12] C. Chen, B. Yu, J. Liu, J. Cao, D. Zhu, Z. Liu, Nucl. Instrum. Methods Phys. Res., B Beam Interact. Mater. Atoms 239 (2005) 433.

[13] W. Zhang, S.H. Brongersma, O. Richard, B. Brijs, R. Palmans, L. Froyen, K. Maex, Microelectron. Eng. 76 (2004) 146. 